$16^{\text {th }}$ International Congress of Metrology, 10004 (2013)

DOI: $10.1051 /$ metrology/201310004

(C) Owned by the authors, published by EDP Sciences, 2013

\title{
Calibration gases for existing air quality directive pollutants at limit values (LV)
}

Tatiana Macé ${ }^{1}$, Jérôme Couette ${ }^{1}$, Frédéric Dijoux ${ }^{1}$, Fabien Mary ${ }^{1}$, Christophe Sutour ${ }^{1}$, Bernhard Niederhauser ${ }^{2}$, Hans-Peter Haerri ${ }^{2}$, Céline Pascale ${ }^{2}$, Jari Walden ${ }^{3}$, Klaus Wirtz ${ }^{4}$ and Viliam Stovcik ${ }^{5}$

\author{
${ }^{1}$ Laboratoire National de métrologie et d'Essais (LNE), 1, rue Gaston Boissier, 75724 Paris Cedex 15, France \\ ${ }^{2}$ Eidgenössisches Institut für Metrologie (METAS), Lindenweg 50, 3003 Bern-Wabern, Switzerland \\ ${ }^{3}$ Finnish Meteorological Institute (FMI), Erik Palmenin aukio 1, 00560 Helsinki, Finland \\ ${ }^{4}$ Federal Environment Agency (Umweltbundesamt, UBA), Paul-Ehrlich Straße 29, 63225 Langen, Germany \\ ${ }^{5}$ Slovensky Metrologicky Ustav (SMU), Karloveska 63, 84255 Bratislava 4, Slovak Republic
}

\begin{abstract}
The European Directive (2008/50/EC) sets up, among other things, the limit values i.e. the maximum allowed concentrations at given time average in the air, for specified pollutants. Calibration of the measurement instruments needs to be performed at regular time intervals. In the framework of an European Joint Research Programme (JRP) named Metrology for Chemical Pollutants in Air (MACPoll) one task aims to provide harmonized dilution methods for air pollutant gases at low concentration for calibration and quality control purposes. The study focuses on the reactive gases nitrogen dioxide and sulphur dioxide at concentration levels corresponding to the limit values given in the European Directive (2008/50/EC). Nitrogen oxide (NO) is studied as well as $\mathrm{NO}_{2}$ because both of them are measured simultaneously for NOx. This work consists in improving the dilution methods for generating calibration standards for $\mathrm{SO}_{2}, \mathrm{NO}, \mathrm{NO}_{2}$ at limit values and to validate them by an interlaboratory comparison.
\end{abstract}

\section{Introduction}

Historically, the main air pollution problems in both developed and rapidly industrialising countries were typically the high levels of smoke and sulphur dioxide $\left(\mathrm{SO}_{2}\right)$ emitted following the combustion of sulphurcontaining fossil fuels such as coal, used for domestic and industrial purposes. These days, the major threat to clean air is now posed by traffic emissions. Vehicles with petrol and diesel engines emit a wide variety of pollutants, principally carbon monoxide (CO), nitrogen oxides $\left(\mathrm{NO}_{\mathrm{x}}\right)$, volatile organic compounds (VOCs) and particulate matter (PM2.5; PM10) which have an increasing impact on urban air quality.

Photochemical reactions resulting from the action of sunlight on nitrogen dioxide $\left(\mathrm{NO}_{2}\right)$ and VOCs, lead to the formation of ozone $\left(\mathrm{O}_{3}\right)$. After formation the ozone takes part in the secondary reaction e.g. with NO and impacts rural areas far from the original emission site as a result of the chemical transformation and long range transport..

Because of the potential impacts of pollutants, welfare and the natural environment, ambient concentrations for a number of pollutants are measured with different sampling and analytical methods at a wide range of rural and urban monitoring sites throughout the world.

\section{Objectives}

In the framework of a Joint Research Programme (JRP) named Metrology for Chemical Pollutants in Air, one task aims to provide harmonized preparative dilution methods of air pollutant gases for calibration and quality control purposes in air quality monitoring where a need for improved methodologies is present. The work focuses on the reactive gases $\mathrm{NO}_{2}$ and $\mathrm{SO}_{2}$ at concentration levels corresponding to the limit values given in the European Directive 2008/50/EC [1] for the measurement of ambient air pollutants. Nitrogen oxide (NO) is studied as well as $\mathrm{NO}_{2}$ because both of them are measured simultaneously for NOx,. This work consists in improving the methods of dynamic generation of calibration standards for $\mathrm{SO}_{2}$, $\mathrm{NO}, \mathrm{NO}_{2}$ at limit values and to validate them by comparison with travelling standards. 
Five National Metrology Institutes are involved in this study, ie LNE (France), FMI (Finland), SMU (Slovak Republic), METAS (Switzeland) and UBA (Germany).

\section{Improving dilution methods}

Different dilution methods are currently used for the preparation of calibration standards for calibration and quality control purposes. The target in this study is to revise some dilution methods for generating calibration standards of $\mathrm{SO}_{2}, \mathrm{NO}$ and $\mathrm{NO}_{2}$ at low concentrations which fulfil with the requirements of the European Directive (2008/50/EC) (see Table 1) with traceability to SI units and with an uncertainty of $3 \%$.

Table 1.Limit values for $\mathrm{SO}_{2}$ and $\mathrm{NO}_{2}$

\begin{tabular}{|l|l|}
\cline { 2 - 2 } \multicolumn{1}{c|}{} & \multicolumn{1}{c|}{ Limit Values (LV) } \\
\hline $\mathrm{SO}_{2}$ & $\begin{array}{l}\text { One hour: } 132 \mathrm{nmol} / \mathrm{mol}^{(1)} \\
\text { One day: } 47 \mathrm{nmol} / \mathrm{mol}^{(1)} \\
\text { Calendar year: } 8 \mathrm{nmol} / \mathrm{mol}^{(2)}\end{array}$ \\
\hline $\mathrm{NO}_{2}$ & $\begin{array}{l}\text { One hour: } 105 \mathrm{nmol} / \mathrm{mol}^{(1)} \\
\text { Calendar year: } 21 \mathrm{nmol} / \mathrm{mol}^{(1)}\end{array}$ \\
\hline
\end{tabular}

(1) European Directive (2008/50/EC) Annex XI/Art. 13

${ }^{(2)}$ European Directive (2008/50/EC) Annex XIII/Art. 14

The measurement range of 40-150 nmol/mol for $\mathrm{SO}_{2}$ (the limit value for calendar year is too low) and of 20-100 $\mathrm{nmol} / \mathrm{mol}$ for $\mathrm{NO}$ and $\mathrm{NO}_{2}$ were selected (there is no limit value for $\mathrm{NO}$, but as NO is normally measured in combination with $\mathrm{NO}_{2}$, the work has been focused on $\mathrm{NO}$ and $\mathrm{NO}_{2}$ at the same measurement range).

Four dilution methods are studied : static dilution $\left(\mathrm{SO}_{2}\right.$ and $\mathrm{NO})$, permeation method $\left(\mathrm{NO}_{2}\right.$ and $\left.\mathrm{SO}_{2}\right)$, dynamic dilution of gas mixtures $\left(\mathrm{NO}, \mathrm{NO}_{2}\right.$ and $\mathrm{SO}_{2}$ ) and gas phase titration $\left(\mathrm{NO}_{2}\right)$ based on the reaction between nitrogen oxide and ozone.

The different source contributions were determined and quantified for each component and for each dilution method between 40 and $150 \mathrm{nmol} / \mathrm{mol}$ for $\mathrm{SO}_{2}$ and between 20 and $100 \mathrm{nmol} / \mathrm{mol}$ for $\mathrm{NO}$ and $\mathrm{NO}_{2}$. The expanded uncertainties calculated for $\mathrm{NO}, \mathrm{NO}_{2}$ and $\mathrm{SO}_{2}$ on the defined measurement ranges are lower than $3 \%$. The main source of uncertainty comes from the impurities in the dilution gas. However, there are another underscored sources of uncertainty on concentrations of generated calibration standards. In this way each laboratory has identified the different steps of the dilution methods which have to be improved. Some examples of improvements which have been done are given in the following paragraphs.

Concerning the static dilution different types of syringes were tested and the individual syringe volume was determined by an independent method based on the weight of masses. The preparation procedure was automated and the timing was defined for each step to improve the repeatability. The data acquisition system such as the temperature logging of all relevant system parts (vessel, housing, syringes, laboratory) and the pressure logging (vessel, laboratory) was improved.

For the dynamic dilution of high concentration gas mixtures the measurement of the flows (dilution flow and gas flow) was studied by comparing different flow measurement techniques to seek the method that leads to the lowest uncertainty for the dynamic gas mixtures at low concentration such as mass-flow controller, critical orifices and laminar flow element: this study showed that mass-flow controller and laminar flow element led to the lowest uncertainties. The influence of possible reactions between the components of the dynamic gas mixture and different container materials (Teflon (PFA), Sulfinert coatings and stainless steel) was also studied.

Concerning the permeation method the weighing process of permeation tubes and the temperature and pressure stability of the permeation device were improved. As for the dynamic dilution of high concentration gas mixtures the influence of possible reactions between the present components of the dynamic gas mixture and different container materials was also studied.

For gas phase titration facility the stability of the ozone generator as well as the analysis of the ozone represents the major contributions to the uncertainty budget. The analysis of the ozone concentration includes also the uncertainty of the zero air. Different ozone generators have been tested and the contribution of the water concentration in the zero air was studied.

\section{Organization of the interlaboratory comparison}

\subsection{Determination of the protocol}

The comparison consists in measuring the analytical concentrations of dynamic gas mixtures at 2 stable low concentrations for each component in a matrix ',air', by each laboratory with the improved dilution methods: for $\mathrm{SO}_{2}$ at $40 \mathrm{nmol} / \mathrm{mol}$ and at $150 \mathrm{nmol} / \mathrm{mol}$ and for $\mathrm{NO}$, $\mathrm{NO}_{2}$ at $20 \mathrm{nmol} / \mathrm{mol}$ and $100 \mathrm{nmol} / \mathrm{mol}$.

The target will be to obtain a comparability between the results better than $2 \%$ for $\mathrm{NO}$ and $\mathrm{SO}_{2}$ and better than $3 \%$ for $\mathrm{NO}_{2}$.

\subsection{Choice of the travelling standards}

For generating the dynamic gas mixtures two travelling standards have been developed by LNE and by METAS.

A device based on dynamic dilution of gas mixtures with very accurate commercial laminar flowmeters (Molbloc/Molbox) has been set up by LNE for NO and $\mathrm{SO}_{2}$ (see Figure 1). 


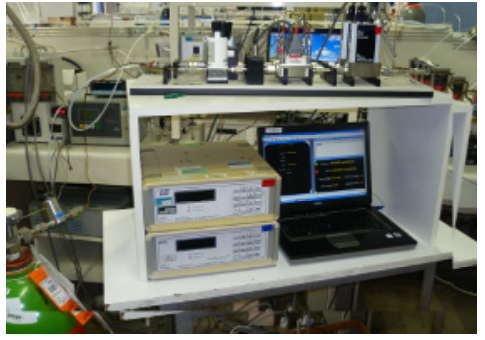

Figure 1.Travelling standard developed by LNE for $\mathrm{NO}$ and $\mathrm{SO}_{2}$

A gas mixture generator based on the permeation method has been built by METAS for $\mathrm{NO}_{2}$ (see Figure 2).

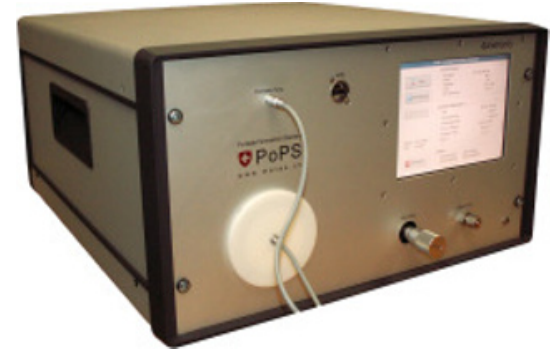

Figure 2. Travelling standard developed by METAS for $\mathrm{NO}_{2}$

\subsection{Characterization of the travelling standard developed by $\mathrm{LNE}$ for $\mathrm{NO}$ and $\mathrm{SO}_{2}$}

The travelling standard developed by LNE is composed of two lines : one for the dilution gas and another one for the gas mixtures (at $5 \mu \mathrm{mol} / \mathrm{mol}$ for $\mathrm{SO}_{2}$ or at $5 \mu \mathrm{mol} / \mathrm{mol}$ for NO) as shown on Figure 3.

Each line consists in a pressure regulator, a very accurate and reproducible flowmeter (Molbloc/Molbox) to adjust the flow rate at a defined value operating in conjunction with a mass-flow controller (MFC) to regulate the flow rate at this value. The Molbloc mass flow element of the component line covers the nominal range of mass flow between $0.1 \mathrm{mg} / \mathrm{s}$ and $1 \mathrm{mg} / \mathrm{s}(5 \mathrm{ml} / \mathrm{min}$ to $50 \mathrm{ml} / \mathrm{min}$ for nitrogen). The Molbloc mass flow element of the dilution line covers the range of mass flow between $10 \mathrm{mg} / \mathrm{s}$ and $100 \mathrm{mg} / \mathrm{s}(0.5 \mathrm{l} / \mathrm{min}$ to $5 \mathrm{l} / \mathrm{min}$ for air $)$. All flowmeters have been calibrated by the gravimetric dynamic method [2][3]; their expanded uncertainty was below $0.3 \%$. Then the dynamic gas mixture is homogenized in a mixing chamber.

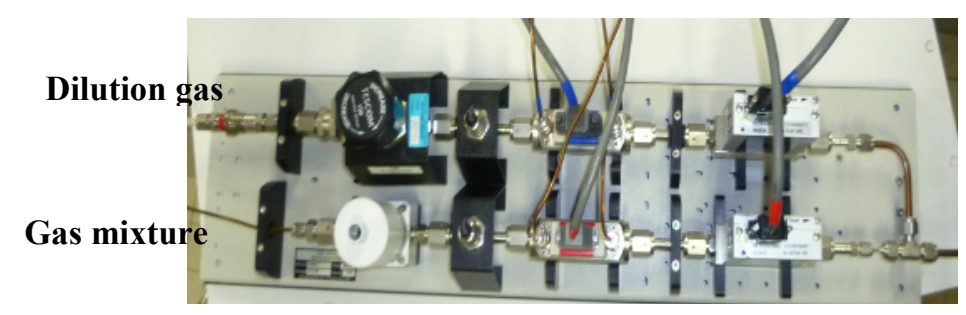

Figure 3.Principle of the travelling standard developed by LNE for $\mathrm{NO}$ and $\mathrm{SO}_{2}$

For generating the dynamic gas mixtures the flow rates of the high concentration gas mixtures or the dilution gas were optimized. The flow rates have to be sufficiently low not to use a high volume of gas and sufficiently high to avoid purging problems.

Different values of flow rates have been tested (see Figure 4) and the results show that the stability time and the concentrations depend on the choice of the flow rates.

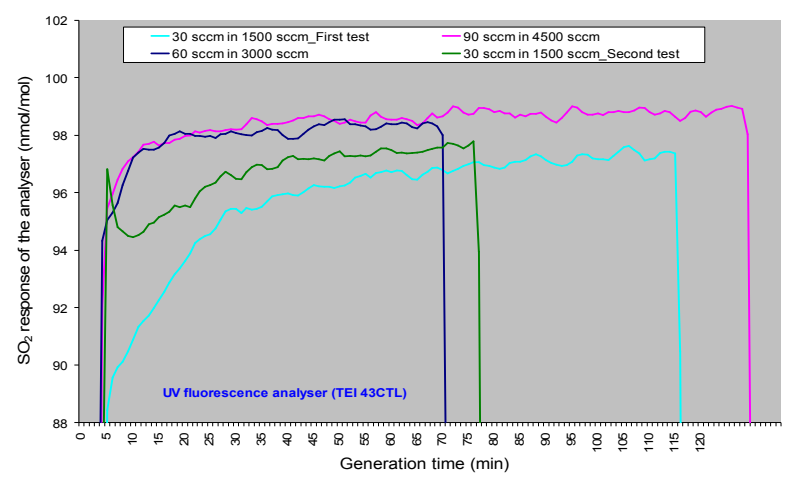

Figure 4.Optimization of the flow rates of the dilution gas and the high concentration gas mixture for $\mathrm{SO}_{2}$

After optimization it has been decided to set the flow rates at the values given in the Table 2 .

Table 2.Values of the flow rates of the dilution gas and the high concentration gas mixture

\begin{tabular}{|c|c|c|c|c|}
\cline { 2 - 5 } \multicolumn{1}{c|}{} & \multicolumn{2}{c|}{$\mathrm{NO}$} & \multicolumn{2}{c|}{$\mathrm{SO}_{2}$} \\
\hline $\begin{array}{c}\text { Concentration } \\
\text { (nmol/mol) }\end{array}$ & 20 & 100 & 40 & 150 \\
\hline $\begin{array}{c}\text { Flow of the high } \\
\text { concentration gas } \\
\text { mixture at } \\
5 \mu \mathrm{mol} / \mathrm{mol}(\mathrm{sccm})\end{array}$ & 17 & 35 & 35 & 46 \\
\hline $\begin{array}{c}\text { Dilution gas flow } \\
\text { (synthetic air) (sccm) }\end{array}$ & 4100 & 1800 & 4100 & 1500 \\
\hline
\end{tabular}

The choice of the materials used in the device is also very important because the materials (tubings, MFC...) must be adapted to the used gases. For example the stabilisation time of the $\mathrm{NO}$ and $\mathrm{SO}_{2}$ concentrations of the generated gas mixtures depends on the type of tubings used between the dilution system and the analyser (see Figure 5).

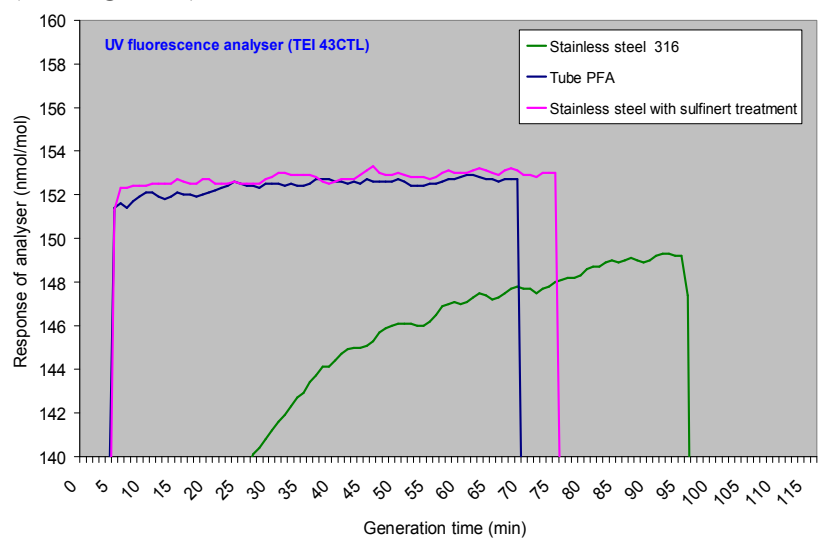

Figure 5.Influence of the materials on the stabilisation time for $\mathrm{SO}_{2}$ 
The Figure 5 shows that the stabilisation is obtained faster with stainless steel with sulfinert treatment and PFA tubings rather than with stainless steel 316 tubings.

As showed in Table 2 the flow rates of the high concentration gas mixtures are low. In this case it's important to reduce the "dead volumes » in contact with the high concentration gas mixture. For reducing the potential «dead volumes » it is used the shortest tubings, a pressure regulator with low volume and without pressure indication and an adapter fitting Type C 1/8 with Sulfinert treatment (low volume) (see Figure 6).
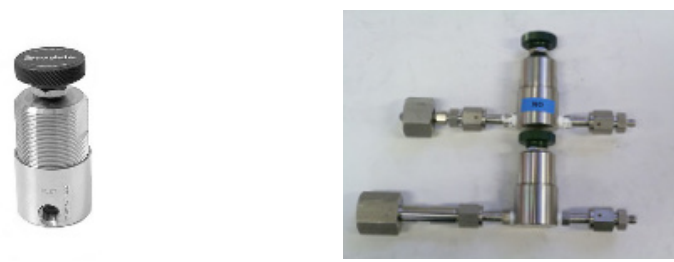

Figure 6. a) (left) Pressure regulator and b) (right) adapter fittings (the new adapter fitting above and the adapter fitting currently used below)

The curves show the influence of the adapter fitting on the concentration of a $\mathrm{SO}_{2}$ gas mixture at $150 \mathrm{nmol} / \mathrm{mol}$. The curves plotted on Figure 7 indicate that the stabilisation is obtained faster with the new adapter fitting rather than with the currently used adapter fitting.

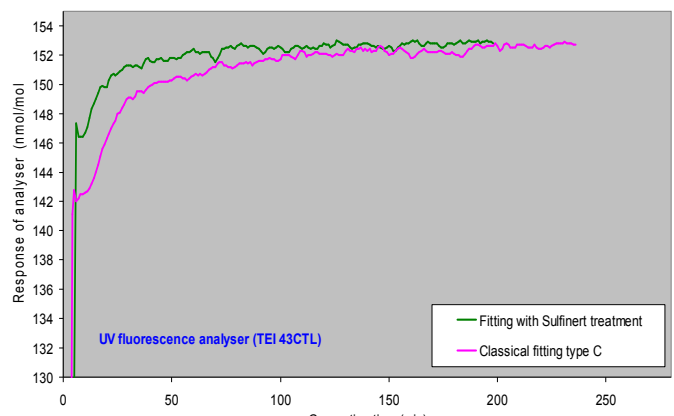

Figure 7.Influence of the type of adapter fitting on the stabilisation time for $\mathrm{SO}_{2}$

After optimizing the device the reproducibility of the NO and $\mathrm{SO}_{2}$ concentrations of the dynamic gas mixtures generated with this travelling standard has been evaluated at 20 and $100 \mathrm{nmol} / \mathrm{mol}$ for $\mathrm{NO}$ and at 40 and 150 $\mathrm{nmol} / \mathrm{mol}$ for $\mathrm{SO}_{2}$.

The analysers (chemiluminescence or UV fluorescence) were calibrated with $\mathrm{NO}$ and $\mathrm{SO}_{2}$ gas mixtures at low concentrations certified with LNE's reference standards. $\mathrm{NO}$ and $\mathrm{SO}_{2}$ dynamic gas mixtures have been generated with the travelling standard at the defined flow rates and injected in the analysers. Their analytical concentrations were measured three times on a day and at 5 different days.

The reproducibilities calculated for each component and each concentration are given in Table 3 .
Table 3.Reproducibility of $\mathrm{NO}$ and $\mathrm{SO}_{2}$ concentrations of the dynamic gas mixtures generated with the travelling standard developed by LNE

\begin{tabular}{|c|c|c|c|c|}
\cline { 2 - 5 } \multicolumn{1}{c|}{} & \multicolumn{2}{c|}{$\mathrm{NO}$} & \multicolumn{2}{c|}{$\mathrm{SO}_{2}$} \\
\hline $\begin{array}{c}\text { Concentration } \\
\text { nmol/mol }\end{array}$ & 20 & 100 & 40 & 150 \\
\hline $\begin{array}{c}\text { Mean value } \\
\text { (nmol/mol) }\end{array}$ & 18.10 & 89.42 & 42.45 & 149.57 \\
\hline $\begin{array}{c}\text { Absolute standard } \\
\text { deviation } \\
\text { (nmol/mol) }\end{array}$ & 0.18 & 0.50 & 0.21 & 0.39 \\
\hline $\begin{array}{c}\text { Relative standard } \\
\text { deviation (\%) }\end{array}$ & 1.01 & 0.56 & 0.49 & 0.26 \\
\hline
\end{tabular}

As the reproducibility of the $\mathrm{NO}$ and $\mathrm{SO}_{2}$ concentrations of the generated dynamic gas mixtures is equal or better than $1 \%$ depending on the component and on the concentrations the device can be used as travelling standard in the interlaboratory comparison.

\subsection{Characterization of the travelling standard developed by METAS for $\mathrm{NO}_{2}$}

The traceable mobile permeation generator was developed by using mass calibrated permeation devices, an oven with SI-traceable temperature and gas flow measurements[4]. The permeation generator is based on a commercial permeation oven, e.g. Dynacalibrator 150 from VICI Valco Instruments Co. Inc. In order to minimise adsorption of analyte, the stainless steel recipient and the downstream tubing are glass coated. In order to equalise the temperature of the incoming gas the inlet tubing is coiled around the heated chamber. The commercial oven is extended by two controlled gas circuits: a constant carrier gas flow (typically 300 $\mathrm{ml} / \mathrm{min}$ ) through the oven and an adjustable dilution flow. Downstream of the permeation oven the two flows are united. The sum of the two flows as measured by the mass flow meter determines the amount of substance fraction of the generated gas mixture for a given permeation mass flow (see Figure 8).

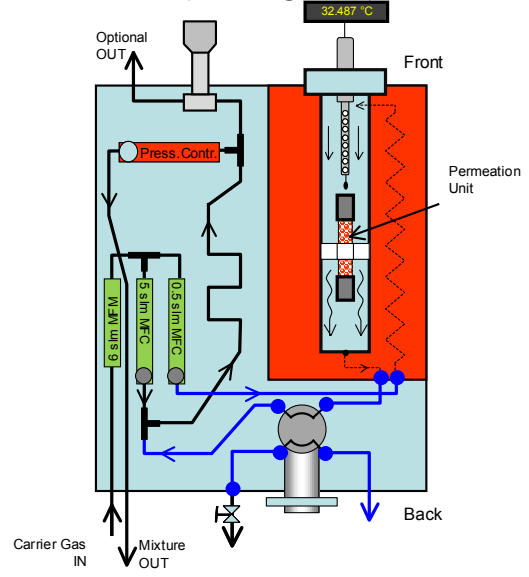

Figure 8.View of the flow schematic with the main components of the mobile permeation standard gas mixture generator 
An important requirement for the inside surfaces of the oven chamber and the tubings is that they must be made of the utmost inert materials towards $\mathrm{NO}_{2}$ and with the lowest possible adsorption rates. Glass largely fulfils these requirements, however the risk of breaking is a clear disadvantage for mobile applications. Stainless steel (SST) with glass coated inner surfaces reveals as an ideal oven material for mobile $\mathrm{NO}_{2}$ generators.

Another requirement was to minimise the fluctuations of the temperature near or at the permeation device.

To measure the temperature of the permeation device, a calibrated temperature sensor was added and located within the oven at the location of the permeation device. It is a FLUKE Hart 1504 Tweener with incorporated leak tight flexible temperature probe, NTC Thermistor (YSI 46000 series) (see Figure 9). It allows the traceable temperature measurement of the permeation device during the gas generation and thus enables the transfer of the temperature measurement from the micro gravimetric standard to the permeation generator.

The drift of the temperature sensor is lower than $0.01^{\circ} \mathrm{C}$ in 100 months for temperatures below $50^{\circ} \mathrm{C}$, its stability is lower than $0.002^{\circ} \mathrm{C}$ and the resolution of reading instrument is equal to $0.001{ }^{\circ} \mathrm{C}$.

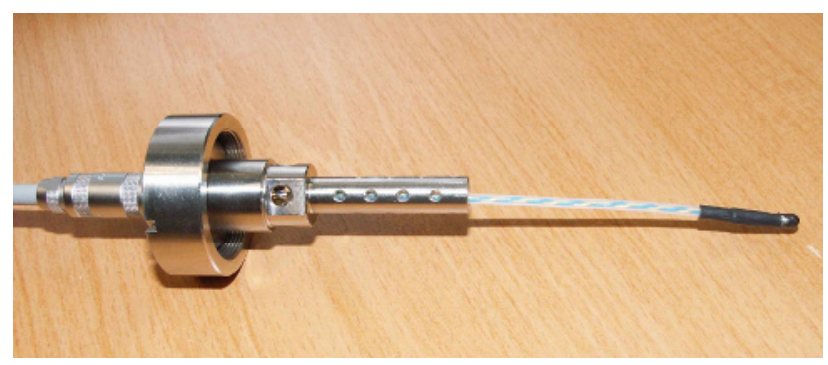

Figure 9.Temperature sensor with connector, flange and gastight feed-through. The tip (sensor element) is located in the chamber close to the permeator

The following Figure 10 shows the temperature at the permeator and the generated $\mathrm{NO}_{2}$ concentration over a period of 5 days.

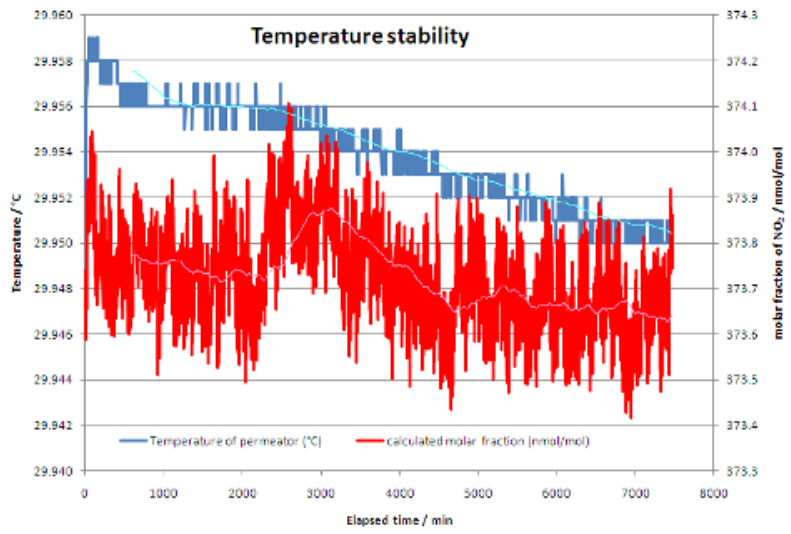

Figure 10.Averaged (blue line) temperature measured close to the permeation device and the calculated and fitted (red line) $\mathrm{NO}_{2}$ concentrations from the prior measured permeation rate and the actual gas flows
A drift of the temperature close to the permeation device equal to $0.015^{\circ} \mathrm{C}$ during 5 days leads to an absolute fluctuation of $0.7 \mathrm{nmol} / \mathrm{mol}$ at a $\mathrm{NO}_{2}$ concentration close to $380 \mathrm{nmol} / \mathrm{mol}$ and a relative one better than $0.2 \%$.

The last requirement was to ensure the stability of the flow rates of carrier and dilution gas flows. Mass flow controllers (MFC) and mass flow meters (MFM) with the latest available technology are used. They are based on the latest CMOS technology, e.g. Red-y smart series based CMOSens ${ }^{\mathrm{TM}}$ by Sensirion. The general rules described in the ISO standard 14511[5] for using MFC's and MFM should be followed.

The chosen flow devices fulfilling the above requirements for the realisation of the described type of permeation generator are the following:

Mass flow controller (MFC) for carrier gas: red-y smart controller, model: GSC-A5TT-BB22 $0.5 \mathrm{slm}$ (normally set to $300 \mathrm{ml} / \mathrm{min}$ ),

Mass flow controller (MFC) for dilution gas: red-y smart controller, model: GSC-B5TT-BB23 5 slm (set between 500 and $5000 \mathrm{ml} / \mathrm{min})$,

Mass flow meter (MFM) for total gas flow: red-y smart meter, model: GSM-B9TT-BN00 $6 \operatorname{sim}$ (600 to 6000 $\mathrm{ml} / \mathrm{min})$.

Only the MFM for the total gas flow is required to be calibrated. Indicative but stable values for the two MFC's are sufficient. The calibration of the MFM is made with purified or synthetic air and nitrogen against the national primary standard for small gas flows. The reproducibility in the total flow range of the $6 \mathrm{~L} / \mathrm{min}$ MFM was $0.35 \%$ relative during a time period of 3 years. For CMOS MFM relative reproducibilities better than $0.1 \%$ can be expected over a 6 months period.

The instantaneous total gas flow was recorded over a period of 5.5 days (see Figure 11) and the $\mathrm{NO}_{2}$ concentrations calculated from the actual flow, assuming a constant permeation rate of the permeator.

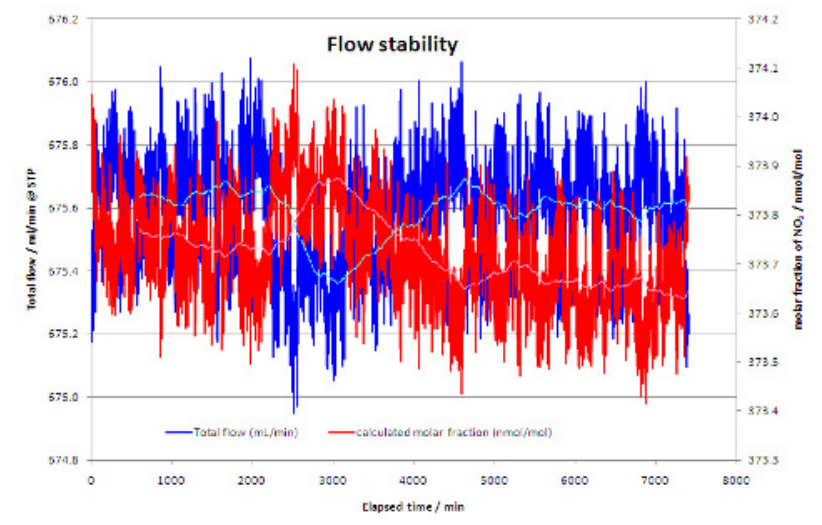

Figure 11.Averaged total gas flow (blue) and calculated and averaged $\mathrm{NO}_{2}$ concentrations (red) over a time period of 5.5 days

The maximum absolute fluctuation of the gas composition due to the flow variation was $0.25 \mathrm{nmol} / \mathrm{mol}$ for a $\mathrm{NO}_{2}$ concentration close to $380 \mathrm{nmol} / \mathrm{mol}$, corresponding to relative fluctuation equal to $0.06 \%$. 
As for the travelling standard developed for $\mathrm{NO}$ and $\mathrm{SO}_{2}$ by LNE the reproducibility of the permeation generator was estimated by recording the $\mathrm{NO}_{2}$ concentration generated close to $50 \mathrm{nmol} / \mathrm{mol}$ during 14 days (see Figure 12).

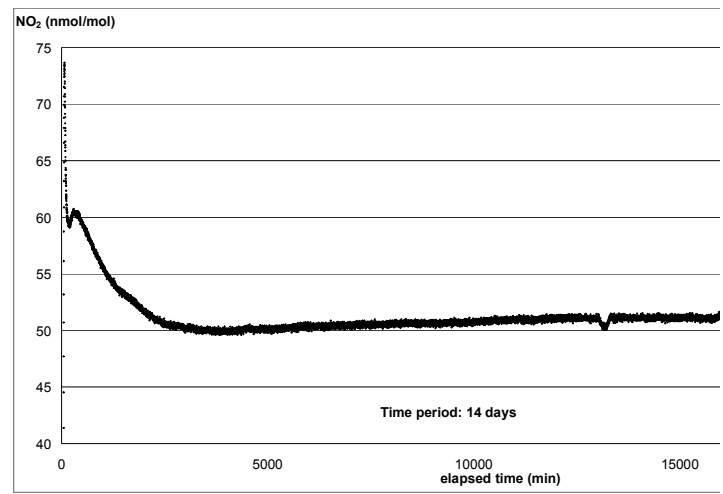

Figure 12. Reproducibility of the $\mathrm{NO}_{2}$ concentrations of the dynamic gas mixtures generated with the travelling standard developed by METAS

The results show that the device can be used as travelling standard in the interlaboratory comparison because of its good reproducibility.

\subsection{Planning of the comparison}

After choosing and characterizing the travelling standards the interlaboratory comparison has been planned. The travelling standards were calibrated by LNE and METAS in April 2013. The comparison was led at METAS in May 2013 for $\mathrm{NO}$ and $\mathrm{NO}_{2}$ and at FMI in June 2013 for $\mathrm{NO}, \mathrm{SO}_{2}$ and $\mathrm{NO}_{2}$. Then the two travelling standards were sent back to LNE and METAS to be calibrated again during July/August to detect a possible drift of the $\mathrm{NO}, \mathrm{NO}_{2}$ and $\mathrm{SO}_{2}$ concentrations over the time. After this calibration the comparison will be done again at SMU in September 2013 for $\mathrm{NO}$ and $\mathrm{SO}_{2}$ and at UBA in October 2013 for $\mathrm{NO}, \mathrm{SO}_{2}$ and $\mathrm{NO}_{2}$. After the interlaboratory comparison the calibration of the two travelling standards will be verified in METAS and LNE in next November (see Figure 13).

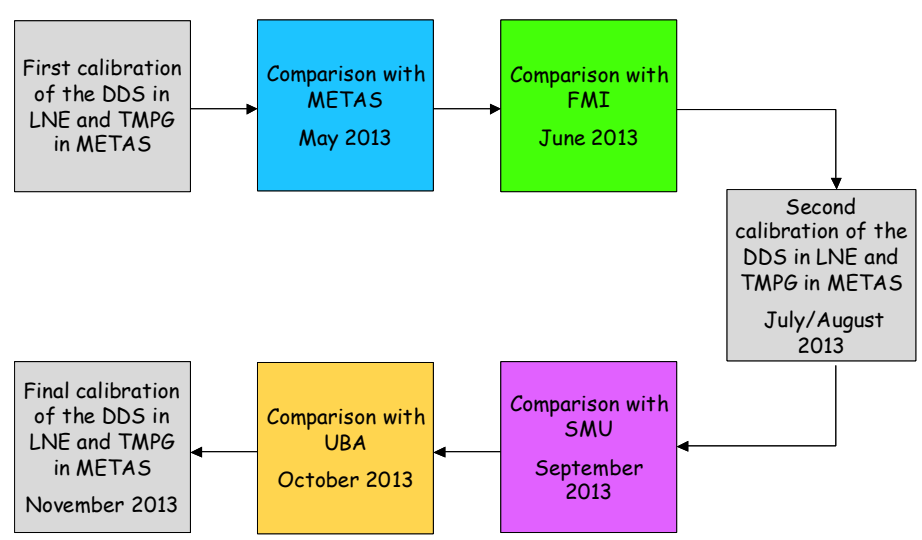

Figure 13.Planning of the interlaboratory comparison

\section{Conclusion}

This European project MACPoll aimed the participants to improve different dilution methods used for generating reference standards for calibration and quality control purposes for ambient air pollutants $\left(\mathrm{NO}, \mathrm{NO}_{2}\right.$ and $\left.\mathrm{SO}_{2}\right)$ at low concentrations (between 20 and $100 \mathrm{nmol} / \mathrm{mol}$ for $\mathrm{NO}, \mathrm{NO}_{2}$ and between 40 and $150 \mathrm{nmol} / \mathrm{mol}$ for $\mathrm{SO}_{2}$ ) which fulfil with the limit values given in the European Directive (2008/50/EC).

Moreover this European project has allowed to develop stable and accurate travelling standards based on permeation for $\mathrm{NO}_{2}$ and on dynamic dilution of high concentration gas mixtures for $\mathrm{NO}$ and $\mathrm{SO}_{2}$.

In parallel three guides are in the course of writing for the different dilution methods and will be available at the beginning of 2014: a first guide on dynamic dilution for $\mathrm{NO}, \mathrm{NO}_{2}$ and $\mathrm{SO}_{2}$ at limit values, a second one on permeation method for $\mathrm{NO}_{2}$ and $\mathrm{SO}_{2}$ at limit values and a third one on static dilution for $\mathrm{NO}$ and $\mathrm{SO}_{2}$ at limit values.

\section{Acknowledgments}

This project, contract number ENV01 MACPoll, runs under the European Metrology Research Programme, a Programme of EURAMET. The EMRP is jointly funded by the EMRP participating countries within EURAMET and by the European Union.

\section{References}

1. Directive 2008/50/EC of the European Parliament and of the Council of 21 May 2008 on ambient air quality and cleaner air for Europe (2008)

2. D. Knopf, J. Barbe, W. Richter, A. Marschal, Comparison of the gas mass flow calibration systems of the BNM-LNE and the PTB, Metrologia, 38, $\mathrm{n}^{\circ} 3,197-$ $202(2001)$

3. B. Niederhauser, J. Barbe, International Comparison: Bilateral comparison of primary low-gas-flow standards between the BNM-LNE and METAS, Metrologia, 39, $n^{\circ} 6,573-578$ (2002)

4. M. Quintilii, H.-P. Haerri: Preparation of SI-traceable calibration gas mixtures by using permeation units, Poster GAS2007 4th Gas Analysis Symposium \& Exhibition (2007)

5. ISO 14511, Measurement of fluid flow in closed conduits — Thermal mass flowmeters (2001)

The results of the interlaboratory comparison will be available at the end of 2013 and disseminated at the beginning of 2014 . 